\title{
Author Correction: Mitochondria-specific drug release and reactive oxygen species burst induced by polyprodrug nanoreactors can enhance chemotherapy
}

\author{
Wenjia Zhang ${ }^{1,2}$, Xianglong Hu (i) ${ }^{1,2}$, Qi Shen ${ }^{1,2} \&$ Da Xing ${ }^{1,2}$
}

Correction to: Nature Communications https://doi.org/10.1038/s41467-019-09566-3, published online 12 April 2019.

This Article contains an error in Fig. 7. In panel d, images depicting NT-PNs and TPP-PNs were inadvertently taken from the Control and cRGD-PNs images, respectively. The correct version of the Figure is shown below as Fig. 1.

Published online: 10 June 2019

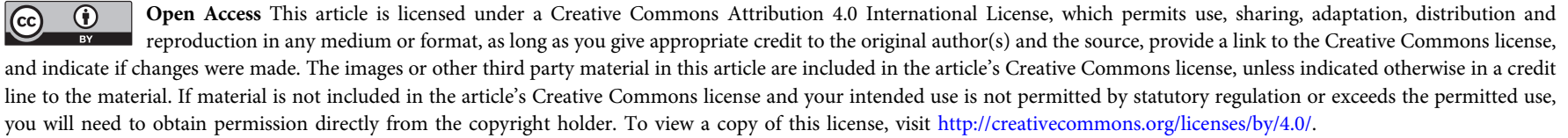

(C) The Author(s) 2019

\footnotetext{
${ }^{1}$ MOE Key Laboratory of Laser Life Science \& Institute of Laser Life Science, South China Normal University, 510631 Guangzhou, China. ${ }^{2}$ College of Biophotonics, South China Normal University, 510631 Guangzhou, China. Correspondence and requests for materials should be addressed to X.H. (email: xlhu@scnu.edu.cn) or to D.X. (email: xingda@scnu.edu.cn)
} 


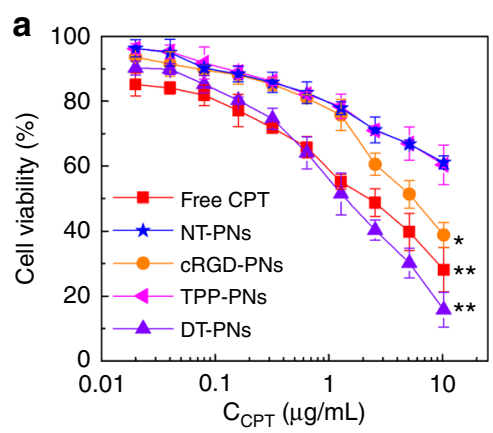

b

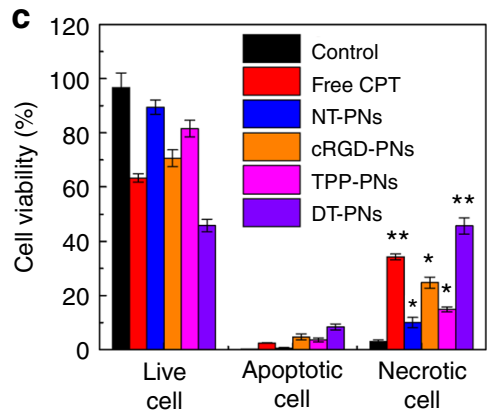

$\bar{\alpha}$
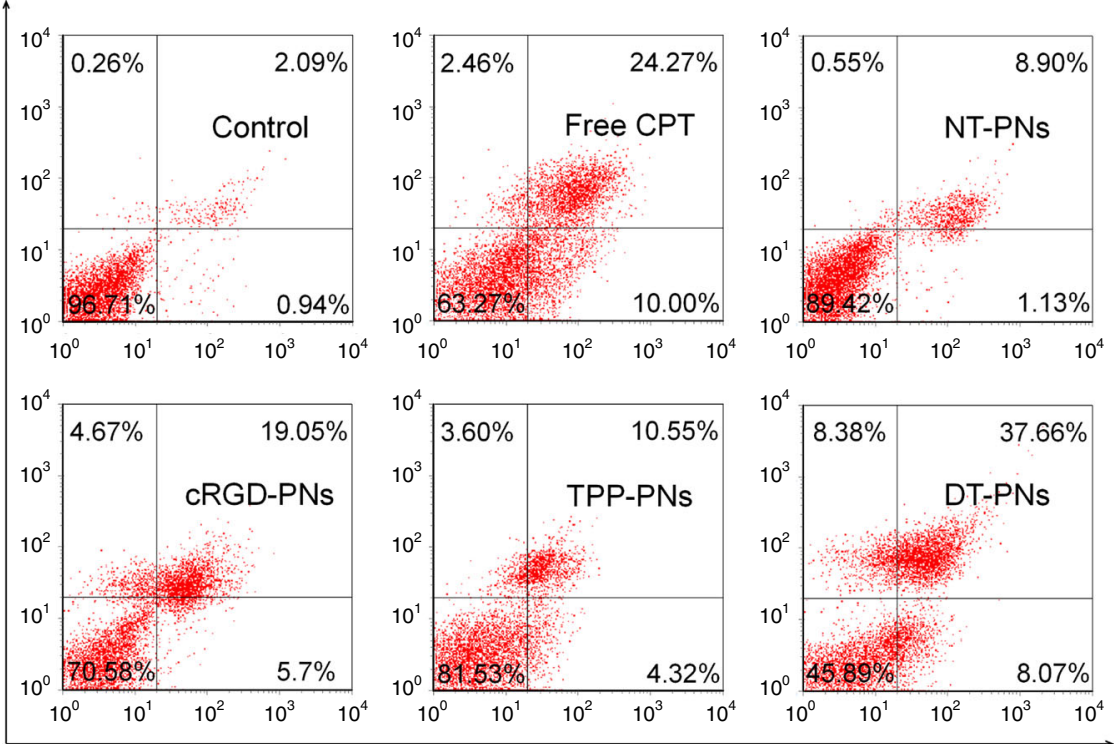

Annexin-V FITC

d

Control

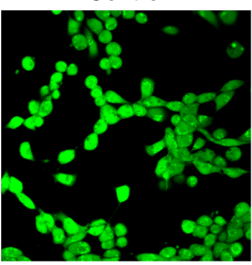

Free CPT

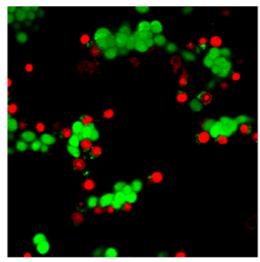

NT-PNs

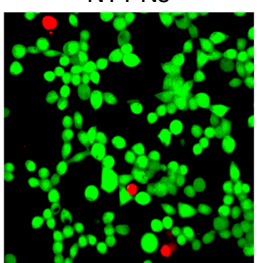

CRGD-PNs
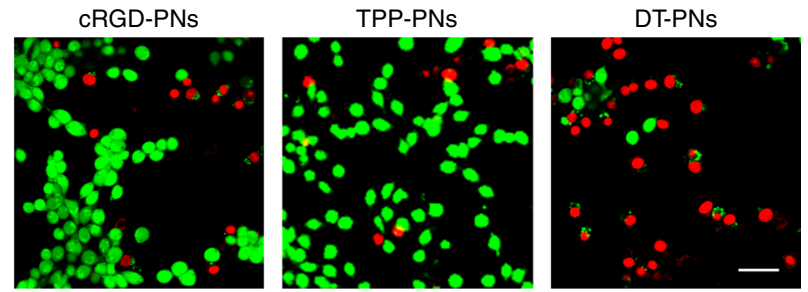

Fig. 1 